\title{
The Global Trade Under the Circumstance of Pandemic- - Taking China as an Example
}

\author{
Haoqing Yang
}

\author{
${ }^{1}$ RDFZ XiShan School, Beijing, China, 100193 \\ *Corresponding author. Email: dannisyanghq@gmail.com
}

\begin{abstract}
During the pandemic, the global trade has been affected a lot. Under the circumstance of the pandemic and the decreasing gross value of global trade over the world, China's foreign trade has increased in 2020. The research has examined mainly on China's foreign trade in order to analyze the causes and effects of the change of global trade. After the research, this paper has concluded that China's economy has increased through 2020 due to its effective pandemic control; however, foreign trade areas are concentrated in Asia and Europe, and regional imbalances are increasing; in the world, globalization will still be the general trend during both pandemic and post-pandemic period.
\end{abstract}

Keywords: pandemic, global trade, China, globalization, protectionism

\section{INTRODUCTION}

According to the statistic released by WTO, the gross value of global trade in 2020 has been declined compared to 2019. The pandemic has broken out for more than a year. It has brought a huge challenge on the global trade. Meanwhile, the protectionism has also been rising up over the world. The development of globalization is struggling. However, the foreign trade of China has been increased in 2020, which is surprisingly. In order to examine the impact of the pandemic on world trade so as to reassure the general trend of globalization.

Since the early 2020, the pandemic has broken out, the pandemic soon spread over the entire world. This situation has impacted a lot on the global economy, especially on the global trade. According to the statista [1], the gross value of global trade in 2020 is around 17582 billion dollars. Compared to the gross value of global trade in 2019, it has decreased by about $7.5 \%$. The decrease can be attributed to so many reasons, but it is mainly because of the pandemic. However, according to the global time [2], the gross value of foreign trade of China in 2020 has increased by $1.9 \%, 32.16$ trillion $\mathrm{RMB}$, compared to the last year. It is surprising that China is the only economy which has had an increase in its gross foreign trade value among the major economies. In order to examine the reasons and effects of the change of the global economy in 2020, this paper will mainly taking China as an sample to do the analysis. 


\section{ANALYSIS ON CHINA'S TRADING SITUATION DURING THE PANDEMIC}

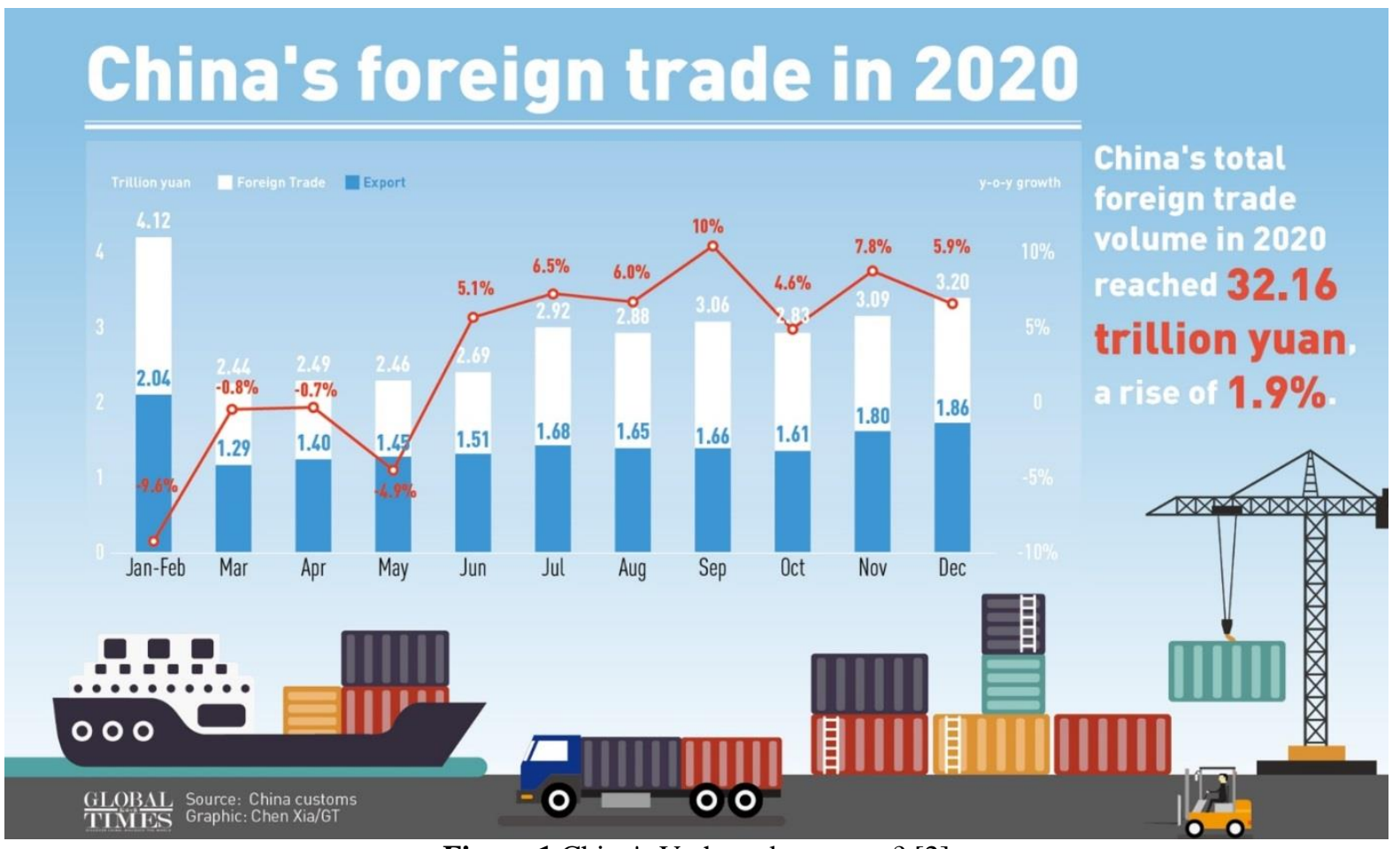

Figure 1 China's V-shaped recovery? [2]

According to the China's National Bureau of Statistics [3], as shown in Figure 1, the GDP of China in the early 2020 has experienced a declined, and a increase later on, thus forming a $\mathrm{V}$-shape. In the beginning of the 2020, COVID-19 has broken out firstly in China, spreading one city to a province eventually to the whole country. Since Chinese government took a series of series of policies, weighting pandemic more than the economy, the economy of China has suffered a lot because of pandemic. In Q1 of 2020, the GDP of China has declined by more than $6 \%$. The economy of China has been almost shut down during Q1 of 2020 . The foreign has also suffered a lot. According to China Daily, due to the epidemic, China's total import and export volume in Q1 was 6.57 trillion yuan, down 6.4\%. Exports were 3.33 trillion yuan, down $11.4 \%$; imports were 3.24 trillion yuan, down $0.7 \%$; the trade surplus was 98.33 billion yuan, down 80.6\% [4]. After a series of strongly regulation of controlling the pandemic, the inflection point came. On March 8th, for the first time the case number of China has been eliminated. In April, the social production and life were bouncing back to the normal state gradually. According to the China's National Bureau of Statistics [3], the GDP of Q2 of China in 2020 has increased by $3.2 \%$. With the foreign trade, from Q2 to Q3, the growth rate has changed from negative value to positive value.

There are three causes of the bouncing economy of China.

The first and the most important cause is the effective control of the pandemic. From the climax to the first time of eliminating the local cases, Chinese government has spent less than 2 months. The policies to control the pandemic are strict and potent: aimed to eliminating all the case numbers. The potent policies not only controlled the pandemic situation effectively, but also ensure the life of human beings. In this way, the government control ensured the social stability and the fundamental of the economy. Only when the life is ensured, does the society own the potentials of the recovery of producing and consuming markets in Q3 and Q4. However, there are also drawbacks of enacting such potent policies onto the society such as the economy indexes of $\mathrm{Q} 1$ and $\mathrm{Q} 2$. The companies and markets had to shut down temporarily. It was a big sacrifice especially for those business whose products are mainly dependent on the imports. However, to the extent of looking at the big picture, the GDP and the foreign trade indexes for the whole year both increased, which looked somewhat surprisingly.

Second, the resilient domestic consumer market also ensured the potential of the recovery of the economy. In 2020 , total retail sales of consumer goods in China reached 41.2 trillion yuan, making China the world's second largest consumer market. Besides, China's savings rate is around $45 \%$, the highest in the world. Even though the high saving rate has some disadvantages, the high saving rate guaranteed the basic daily cost of Chinese people during the pandemic and also promised the potential of the bouncing consumption in Q3 and Q4. Therefore, both of the factors protected the basis of the China's economy so as 
to boost the need for imports. Finally, medical supplies export has contributed a lot to the foreign trade of China during the pandemic. According to the latest data released by China's General Administration of Customs [5], In the first half of this year, China's exports of medicinal materials and medicines increased by $93.6 \%$, and private enterprises' exports of medicinal materials and medicines increased by $70.8 \%$. Meanwhile, China has exported more than 500 million doses of COVID-19 vaccines and stock solutions to 112 countries and regions. According to the latest WTO report on global trade in medical supplies, the global trade in medical supplies grew by $16.3 \%$ in 2020 . China became the largest exporter of key medical products in the fight against COVID-19 in that year, with exports of \$105 billion (about 647.2 billion yuan). This boosted overall export growth by 1.9 percentage points.

The other trend of the foreign trade of China is the increasing RTAs trades. During the pandemic, In 2020, China's import and export volume of goods to ASEAN reached a new high, and ASEAN surpassed the EU to become China's largest trading partner. In addition, the formal signing of RCEP in December 2020 also brought a large number of trades in Asia. According to statistics released by China's General Administration of Customs, in 2020, China's import and export of goods to RCEP member countries exceeded 10 trillion yuan. Furthermore, since 2013 China has actively promoted the One Belt One Road Initiative, and its import and export volume of goods to countries along the Belt and Road has constantly hit new highs, reaching 9.37 trillion yuan in 2020 . As considered the conditions above, it can be clearly seen that the regional trades of China has been increasing rapidly these years. For a long time is there a comparison between WTO and RTAs. Some scholars assert that RTAs are kind of protectionism which may contradict with the WTO, with the globalization, or may even induce economic locks in the world. However, this paper considers that RTAs are not opposite to the WTO in general. RTAs can actually benefit the globalization under proper regulation especially during the period of pandemic.

\section{Evolution of Regional Trade Agreements in the world, 1948-2021}

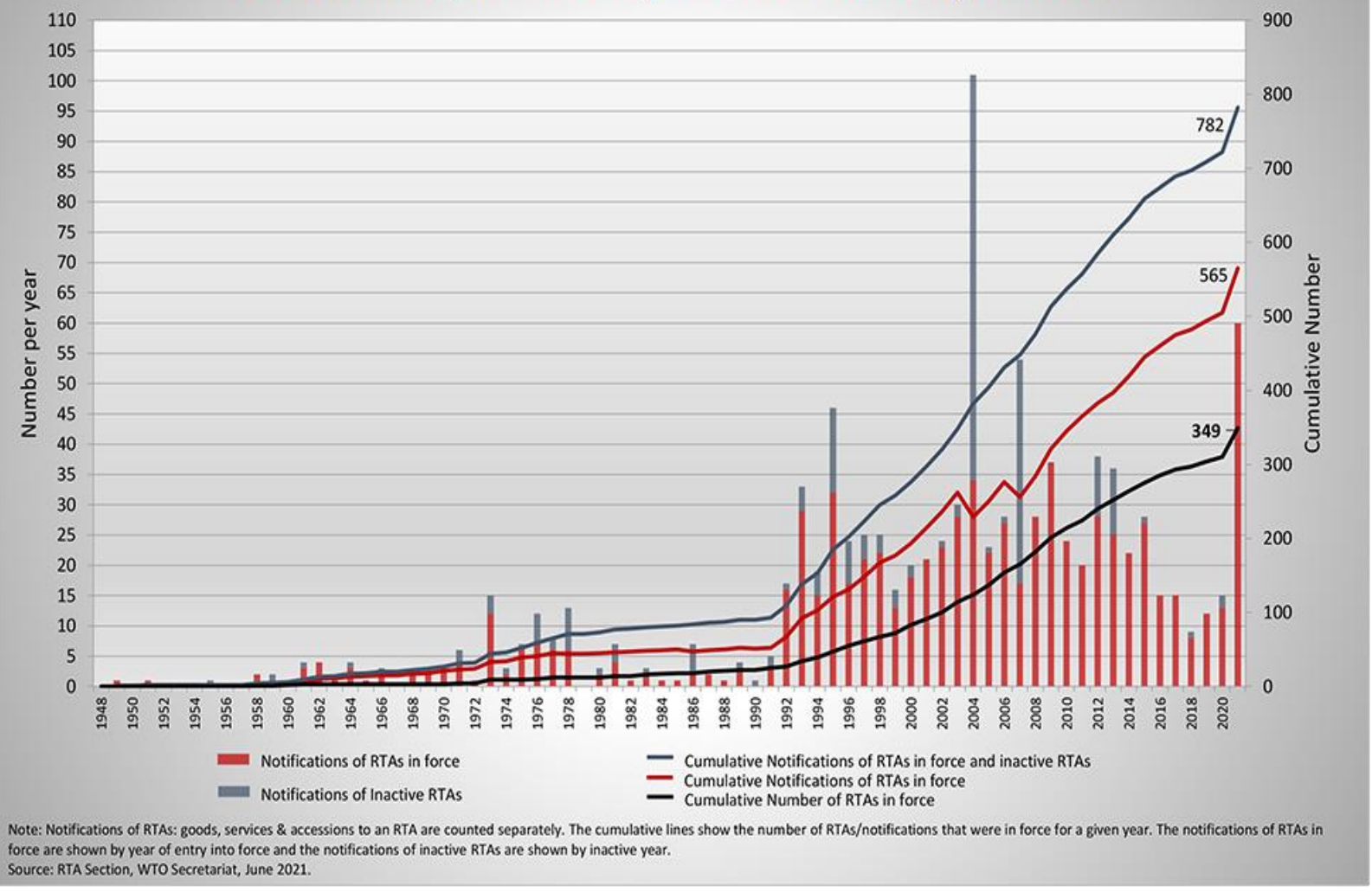

Figure 2 Evolution of Regional Trade Agreements in the world,1948-2021 [6]

According to the statistics released by WTO, shown in Figure 2 above, as of 15 June 2021, 349 RTAs were in force [6]. There are so many reasons behind the huge increase of the RTAs.

Firstly, WTO cannot always effectively promote the trades between all the countries. The probability of rising controversy is grater compared that of in RTAs.
As a result, the controversies always decrease the efficiency. From the regional perspective, due to the fragility of their own economies, some countries are more inclined to participate in small regional economic organizations and build closer economic cooperation with neighboring countries than participating in globalization. It can be seen that under the circumstance 
that WTO still exists, countries in the world still need regional trade agreements.

Secondly, not only do we need to look at the discrepancies between the principles of RTAs and that of WTO, but also need to look at the actual economic growth which the RTAs brought to the world. Take the RCEP as an example, assigned successfully in 2020 during the pandemic, the FREE trade areas of RCEP countries and regions cover about 2.37 billion people, with a combined GDP of nearly us $\$ 25.7$ trillion, and about US $\$ 10.7$ trillion in foreign trade in goods, accounting for nearly $30 \%$ of the global total. It is the largest free trade area in the world and one of the most dynamic regions in the world economy. The member states of the RCEP are diverse, some are developed country like Japan, some are developing country like China. There is a consensus between all the member states which is to pursue the economic growth and it is also the greatest goal of all the countries during the pandemic. Once the economic growths happen between these countries, the fundamental economy of part of the world economy would be ensured and the people in these countries will also have a greater purchasing power to purchase more products whether from the RTA countries or outside the RTA countries. All in all, during the pandemic, globalization should not be limited by the traditional doctrines. In contrast, we need to look at the big picture, clearly see that the long-term interests of the growth of RTAs. However, we also need to be careful about the regulation of RTAs. All the RTAs should be inclusive instead of being conclusive to other countries. Besides, RTAs should be only focus on the economic growths rather than focusing on ideologies or military which may induce the unwanted results like wars.

Thirdly, the protectionism has been bouncing during recent several years. However, it is clearly to see that the globalization will still be the general trend in the future. Take the trade war between China and America as an example. The trade war has begun since 2018 and the trade barrier have still been existing until now. According to the statistics released by US Department of Commerce, the deficit with China increased 22\%. The trade balance between America and China apparently have not been affected remarkably by the trade war [7]. We can actually see that the trade war cannot force the market to change its trade balance. Instead, the deficit of America with China has increased during past two years. This phenomenon concludes clearly that globalization has already established firmly in the world. Almost all the country cannot easily change their trade balances with other countries. The seemingly independent economies of the countries have already connected with others. The trend of the globalization is still clear. Take the pandemic as an example. According to the statistics released by WTO[8], during the 2020, the global trade in medical supplies grew by $16.3 \%$ in 2020 . And this is not only about economy, it is also about saving lives in the world. We cannot imagine what would be the world looking like without such trades in medical supplies. The stability of the entire world would be threatened, and lots of more conflicts might have happened as well due to the unstable world. Surprisingly: the global total value of trade in goods and products are in a decline, but the trade in services is still rising. The author of paper asserts that the increasing trade in services is a positive change but the decreasing trade in products will probably impose a negative impact on the global economy. Products and goods are parts of manufacturing, which is the base of the employment and consumption. It is closely related to people's livelihoods over the world. If the fraction of manufacturing continues to decline, then millions of billions people would probably lose jobs and the supply of the basic merchandise would not be ensured. So, we should pose enough concern on this question, regulate the global market properly, and make sure that the basic production and manufacturing will not suffer from the decreasing trend.

\section{CONCLUSION}

The pandemic has posed a big challenge to the world trade. Whereas, China's foreign trade value has been surprisingly increased for three reasons: effective pandemic control; resilient consuming market; the export of medical supplies. Also, the engagements of China in the RTAs also became more dynamic during the pandemic. Even though the regional trade imbalance has been increased, the engagements in RTAs will contribute to the globalization in the long-term interests. Besides, the RTAs like RCEP has contributed a lot to the world economy in the world economy during the pandemic so that we should encourage the development of the RTAs. Nevertheless, the proper regulation to the development of RTAs is also crucial: RTAs should be inclusive and should only focus on economic field. The general trend of globalization is seen more clearly during the pandemic. World trade can not only affect the economy, but it can save lives during hard times. Therefore, China should keep holding the banner of globalization in the future.

\section{AUTHORS' CONTRIBUTIONS} Yang.

This paper is independently completed by Haoqing

\section{ACKNOWLEDGMENTS}

Firstly, I appreciated the efforts of Professor Michael Beckley for his excellent lectures to me and constructive advices on this paper. Also, I appreciated the efforts of my teaching assistance-Chunyu Lin for her patient and 
detailed instruction academically and non-academically about my confusions on International Relations.

\section{REFERENCES}

[1] Statista, Trends in global export value of trade in goods from 1950 to 2020, Retrieved from https://www.statista.com/statistics/264682/worldwi de-export-volume-in-the-trade-since-1950/

[2] Global Times, China's foreign trade in 2020, January 14th 2020, retrieved from https://www.globaltimes.cn/page/202101/1212782. shtml

[3] China's National Bureau of Statistics, China's V shape Recovery? Retrieved from https://graphics.reuters.com/CHINA-ECONOMY/ GDP/xklpymzdzpg/media-embed.html

[4] Zhong Nan, China's foreign trade volume falls $6.4 \%$ in Q1, April 14th 2020, Retrieved from https://global.chinadaily.com.cn/a/202004/14/WS5 e952001a3105d50a3d16086.html
[5] The State Council Information Office, SCIO briefing on China's import and export in the first half of 2021, July 13th 2021, retrieved from http://english.scio.gov.cn/pressroom/node_8024959 .htm

[6] WTO, Regional trade agreements, Retrieved from https://www.wto.org/english/tratop_e/region_e/regi on_e.htm

[7] Jeff Cox, U.S. trade deficit surges to record; shortfall with China keeps rising, May 4 2021, Retrieved from https://www.cnbc.com/2021/05/04/us-trade-deficitsurges-to-new-record-shortfall-with-china-rises.ht $\mathrm{ml}$

[8] UNB News, Global trade in medical goods up $16.3 \%$ in 2020, August 1st 2021, Retrieved from https://unb.com.bd/category/World/global-trade-inmedical-goods-up-163-in-2020-wto/76467 